\title{
Trivalent cations switch the selectivity in nanopores
}

\author{
Alberto G. Albesa • Matías Rafti • José L. Vicente
}

Received: 14 September 2012 / Accepted: 7 January 2013 /Published online: 24 January 2013

(C) Springer-Verlag Berlin Heidelberg 2013

\begin{abstract}
In this letter, we study the effect of cation charge on anion selectivity in the pore using grand canonical Monte Carlo simulations. The mechanism of anion selectivity inside nanopores was found to be primarily a consequence of the screening of negative charges by the cations. In the case of monovalent cations, screening was not very effective and anions were rejected. We found an 'off-state' at high $\mathrm{pH}$ and an 'on-state' at low $\mathrm{pH}$. When there are divalent cations, screening is good and there is no rejection of the anion. The concentration of anions at high $\mathrm{pH}$ is similar to that at low $\mathrm{pH}$. The system is always in an 'on-state'. Trivalent cations show an inverse selectivity mechanism: at high $\mathrm{pH}$ the concentration is higher than at low $\mathrm{pH}$, i.e., the pore is in the 'on-state' at high $\mathrm{pH}$ and in the 'off-state' at low $\mathrm{pH}$.
\end{abstract}

Keywords Polyelectrolyte · Ionic channel · Calcium gate · Anioinic selectivity $\cdot$ Monte Carlo simulation

\section{Introduction}

Ion channels are fundamental to a wide range of biological processes including cell volume regulation, movement, and generation of electrical signals. Ion channel proteins pass ions through the cell membrane, forming pores through which the ions diffuse down their electrochemical gradient across the membrane [1].

In some biological channels, activation of the pores can be triggered by changes in the local concentration of protons, which ultimately switches ionic transport from an "off"

\footnotetext{
A. G. Albesa $(\triangle) \cdot$ M. Rafti $\cdot$ J. L. Vicente Instituto de Investigaciones Fisicoquímicas Teóricas y Aplicadas (INIFTA), Dep. de Química, Fac. Ciencias. Exactas, UNLP, CC 16 Suc. 4, B1904DPI, La Plata, Argentina

e-mail: albesa@inifta.unlp.edu.ar
}

state, in which no or low ionic current passes through the channels, to an "on" state evidenced by a high transmembrane ionic current [2-4].

So far, most explanations of this phenomenon have been based on the notion that the "conducting" and "non-conducting" states represent "open" and "closed" configurations of the channel, and that the transition between them results from physicochemical changes in the channel environment [1]. In recent years many theoretical studies have sought to develop tools to understand these mechanisms [5-8].

However, biological systems are very complex. For many years there has been the idea to create nanostructured hybrid systems that can operate in a manner similar to biological ion channels and pores [9]. This includes the search for new platforms that allow the selective transport of ionic species derived from a wide variety of technological applications that depend on "gated" transport processes, such as ultrafiltration controlled delivery [10], or even proton-gated devices based on aligned tubular mesoporous silica [11].

A comprehension of the mechanisms by which ion channels regulate the transport of molecules and electric signal transduction at the molecular level is crucial for building ionic circuits in the emerging field of nanofluidics [12]. Besides their importance in biotechnological and analytical applications [13-16], the study of synthetic biomimetic materials serves to understand the complex processes that occur in cells as they are simple enough to make theoretical models.

Martínez-Máñez and co-workers [17] reported the first gated hybrid mesostructured system operating in aqueous solution and controlled ionically by $\mathrm{pH}$ modulation. A pH-driven open/close mechanism was observed to arise from the hydrogen-bonding interaction between amines at neutral $\mathrm{pH}$ (open gate) and Coulombic repulsions at acidic $\mathrm{pH}$ between closely located polyammoniums at the pore openings (closed gate). In additional to the $\mathrm{pH}$-driven protocol, opening/closing of the gate-like ensemble can also be modulated via an anion-controlled mechanism. 
Brunsen et al. [18] recently described the creation of hybrid mesostructured interfaces with reversible gate-like transport properties that can be controlled by chemical inputs such as protons or calcium ions. In this letter, we study the effect of cation charge on anion selectivity in the pore using grand canonical Monte Carlo simulations [19, 20].

\section{Methods}

For the simulations we used a system containing a 5-nm diameter pore. The simulation box used had a length of $20 \mathrm{~nm}$. The pore has 36 polymer chains. The monomers in the polymer are weak polyelectrolytes that have the following acid-base equilibrium:

$$
\begin{array}{ll}
\text { - } & \mathrm{BH} \rightarrow \mathrm{B}^{-}+\mathrm{H}^{+} \quad \mathrm{Ka} 1 \\
\text { - } & \mathrm{VH} \rightarrow \mathrm{V}^{-}+\mathrm{H}^{+} \mathrm{Ka} 2
\end{array}
$$

Each polymer chain has eight subunits, four of each type, and the $\mathrm{pKa}$ values are $\mathrm{pKa} 1=4.4$ and $\mathrm{pKa} 2=7.7$, i.e., similar to the $\mathrm{pKa}$ values of the phosphate group. The radius of the monomer unit is $0.3 \mathrm{~nm}$. The excluded volume was taken into account by considering a hard sphere potential between the monomers and the ions.

The conformational search was performed by allowing the monomers in the chain to rotate around a random angle between $\pi$ and $2 \pi$.

The acidic behavior was investigated in a grand canonical ensemble. A monomer was picked at random, and an attempt made to switch its charge state. The change in (free) energy, $\Delta \mathrm{E}$, governing the success of the attempt, was composed of the change in the Coulombic interactions between monomers, cations and anions , $\Delta \mathrm{E}$, and the free energy change corresponding to the acid-base reaction of an isolated monomer [21, 22],

$\Delta E=\Delta E_{\text {total }} \pm k_{\mathrm{B}} \mathrm{T} \ln 10\left(\mathrm{pH}-\mathrm{pK}_{\mathrm{i}}\right)$

where $\mathrm{pH}$ is the $\mathrm{pH}$ of the system, and $\mathrm{pK}_{\mathrm{i}}$ is the intrinsic $\mathrm{pKa}$ of a monomer. A plus sign indicates that the monomer is to be protonated, and the minus sign that it is to be deprotonated.

To study the effect of salts we have performed simulations, also in the grand canonical ensemble, in which the system was in equilibrium with a bath of salt; the salts were $\mathrm{CA}(0.002 \mathrm{M}), \mathrm{CA}_{2} 0.001 \mathrm{M}$, and $\mathrm{CA}_{3} 0.00666 \mathrm{M}, \mathrm{C}$ and $\mathrm{A}$
Fig. 1 Dissociation degree as function of external $\mathrm{pH}$

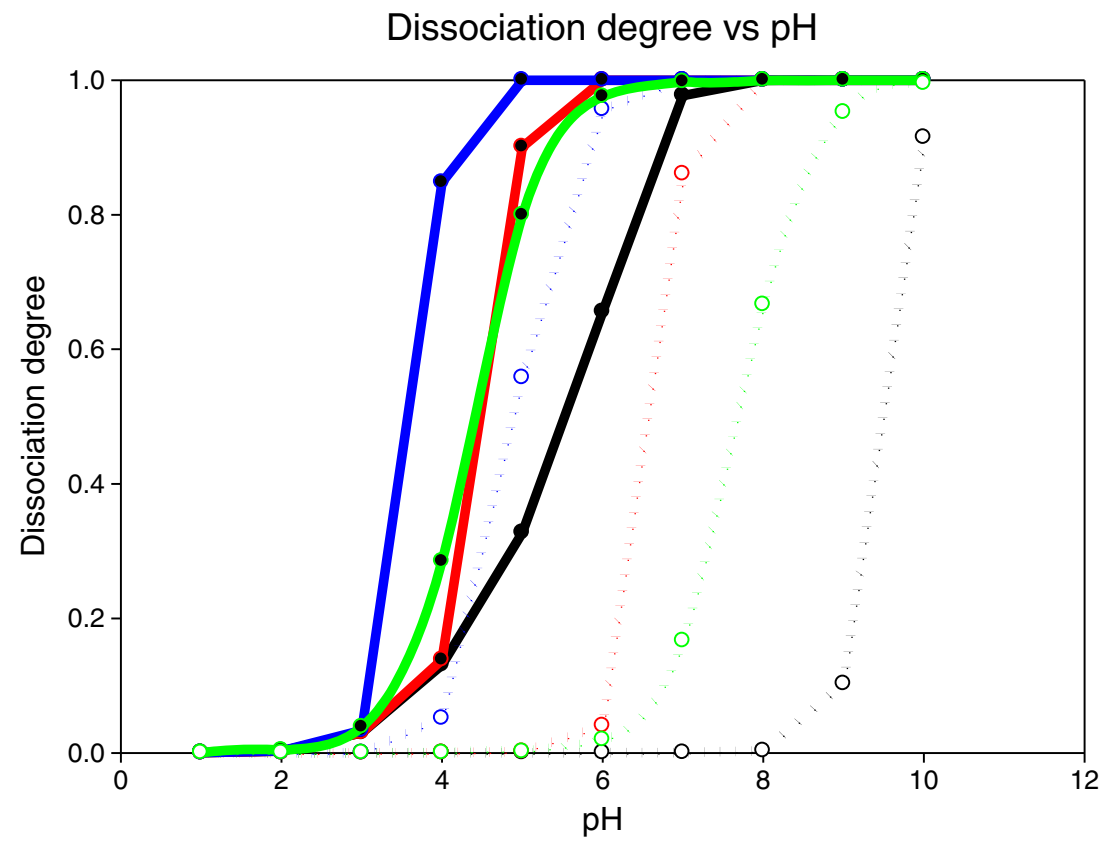

$1^{\circ}$ Protonation with $\mathrm{C}^{+} 0.002 \mathrm{M}$

10 , 29Protonation with $\mathrm{C}^{+} 0.002 \mathrm{M}$

$\rightarrow 1$ 19Protonation with $\mathrm{C}^{++} 0.001 \mathrm{M}$

1. 0 , 2oProtonation with $\mathrm{C}^{++} 0.001 \mathrm{M}$

19Protonation with $\mathrm{C}^{+++} 0.00066 \mathrm{M}$

1 10 , 2oProtonation with $\mathrm{C}^{+++} 0.00066 \mathrm{M}$

- 10Protonation free monomer

10) 2oProtonation free monomer 
being generic cations and anions in such a way that the anion concentration in the bulk is always the same $(0.002 \mathrm{M})$. We determined the chemical potentials needed to establish prescribed bulk concentrations of the bath solution by a performing separate grand canonical ensemble simulations in a large cubic cell with periodic boundary conditions. In all simulations, the size of the anions and cations were identical in order to focus only on the effect of charge.
Fig. 2a,b Anion concentration as function of external $\mathrm{pH}$. a

Normal scale, b logarithmic scale
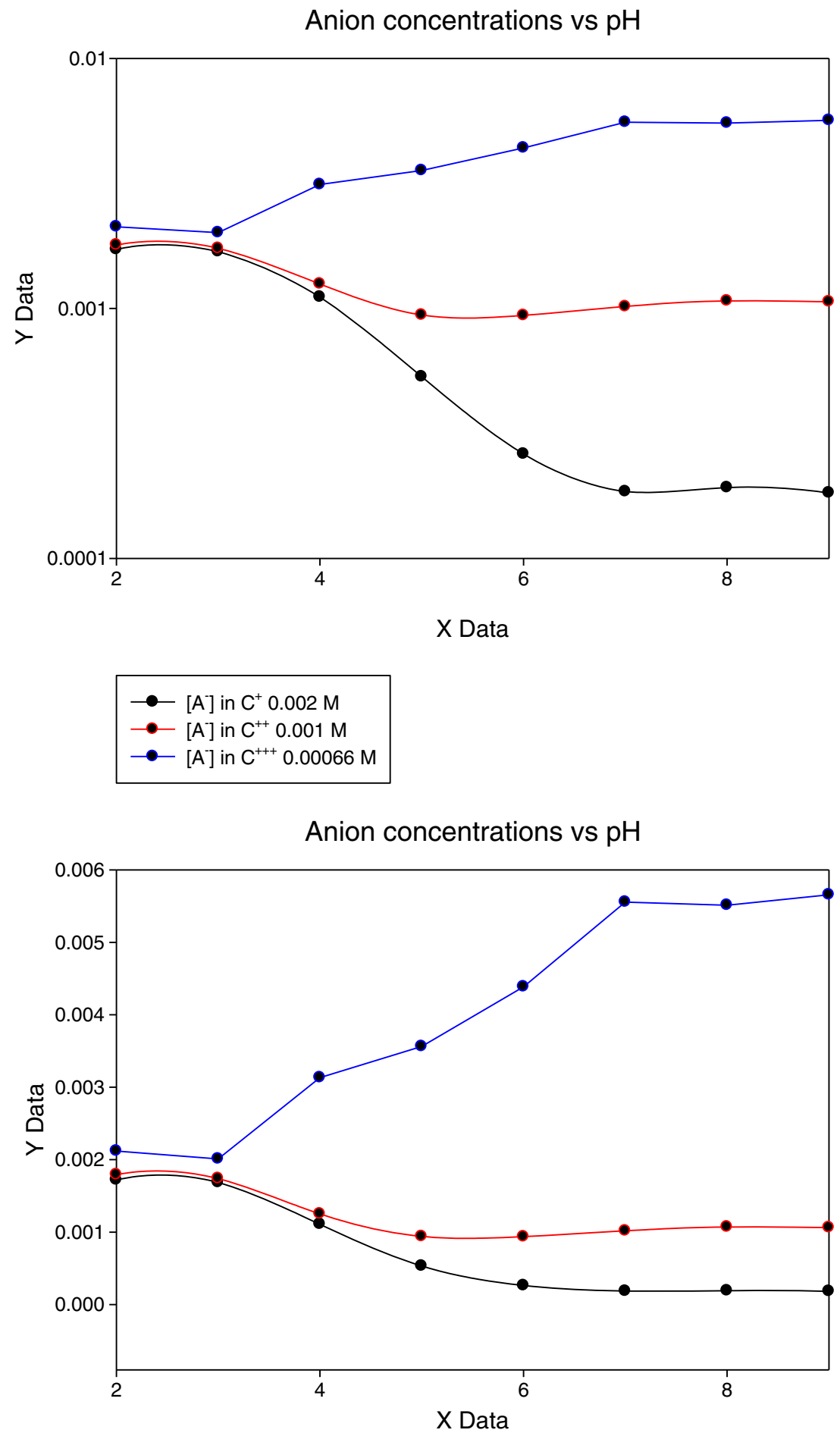

$$
\begin{aligned}
& \longrightarrow\left[A^{-}\right] \text {in } C^{+} 0.002 \mathrm{M} \\
& \because\left[A^{-}\right] \text {in } C^{++} 0.001 \mathrm{M} \\
& \longrightarrow\left[A^{-}\right] \text {in } C^{+++} 0.00066 \mathrm{M}
\end{aligned}
$$




\section{Results and discussion}

Figure 1 shows the dissociation degree of the polymers for the different kind of salts as a function of the external $\mathrm{pH}$.

The first conclusion that can be drawn from Fig. 1 is that, when there is a monovalent salt, the higher local density of polyacid promotes a shift in the acid-base equilibrium in order to minimize the electrostatic repulsions. In other words, the system pays in chemical free energy to reduce the electrostatic repulsions and to avoid the localization of a very high concentration of ions, i.e., counterion confinement.

The degree of protonation seen in Fig. 1 shows that the acidbase equilibrium is not shifted as much with the divalent cation.

In multivalent salts, the shifts in the acid-base equilibrium are opposite to the above, i.e., the system tends to deprotonate the monomers more than when there are free monomers. This means that multivalent cations promote the dissociation of monomers in order to increase the electrostatic energy between monomers and cations. This effect is more evident in monomers with low $\mathrm{pKa}$.

The degree of polymer charge is affected greatly by charge regulation and nanoconfinement effects. This behavior has important consequences for anion selectivity, as can be seen in Fig. 2.

From Fig. 1 we can observe that, at $\mathrm{pH} 2$, the polymers have no charge; this is also reflected in Fig. 2 by noting that the anion concentration at this $\mathrm{pH}$ is similar in the three salts. At $\mathrm{pH} 8$ there are significant differences in the anion concentrations. In the monovalent salt, the anion concentration is approximately 44 times less than the concentration at $\mathrm{pH} 2$. For the divalent salt the change is not as pronounced, at a concentration only two times less than at $\mathrm{pH} 2$, and at a concentration twice that $\mathrm{pH} 2$ for the trivalent salt.

The simulation results indicate that the ionic concentration characteristics are determined by electrostatic modulation originating from the presence of both the polymer brush and the counterions. A charged nanopore can have all these transport properties by changing the ion species. Moreover, the cation versus anion selectivity of the pores can be changed. We find that divalent and trivalent cations produce localized charge inversion that changes the effective pore surface charge profile from negative to positive. These effects are reversible so that the transport and selectivity characteristics of ionic devices can be tuned, much as the gate voltage tunes the properties of a semiconductor.

These results suggest a Donnan-type rejection mechanism, dominated by electrostatic interactions between fixed membrane charges and mobile ions [23]. The observed sensitivity of the rejection to the solution $\mathrm{pH}$ and electrostatic screening length suggests that electrostatic interactions dominate over steric effects in governing ion rejection. The observed trends are in agreement with Donnan membrane equilibrium theory.

The simulation results are in agreement with the experimental works done by He et al. [20], where they have shown that the effective surface charge profile changes with ion species. These results also agree with the work of Brunsen et al. [18] and Gurnev and Bezrukov [24], who find that the accumulation of multivalent ions at the membrane surface
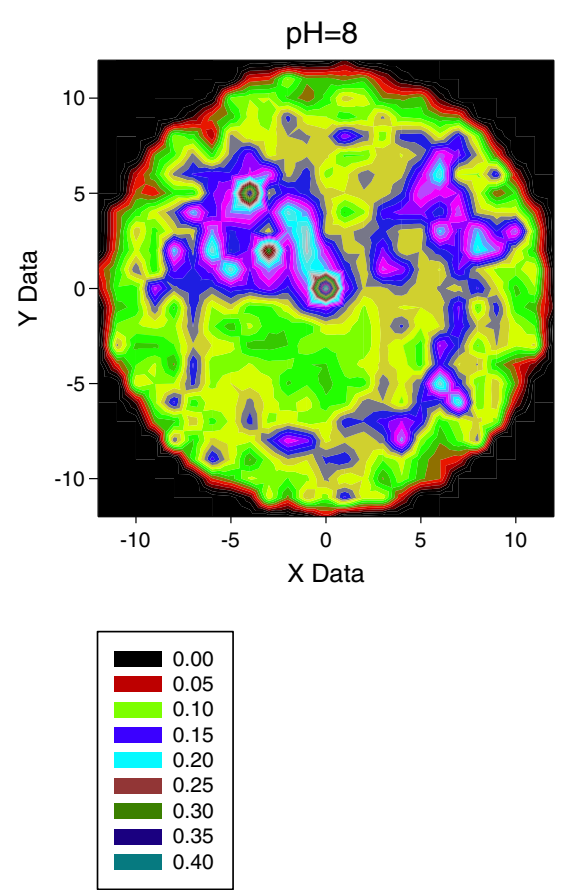
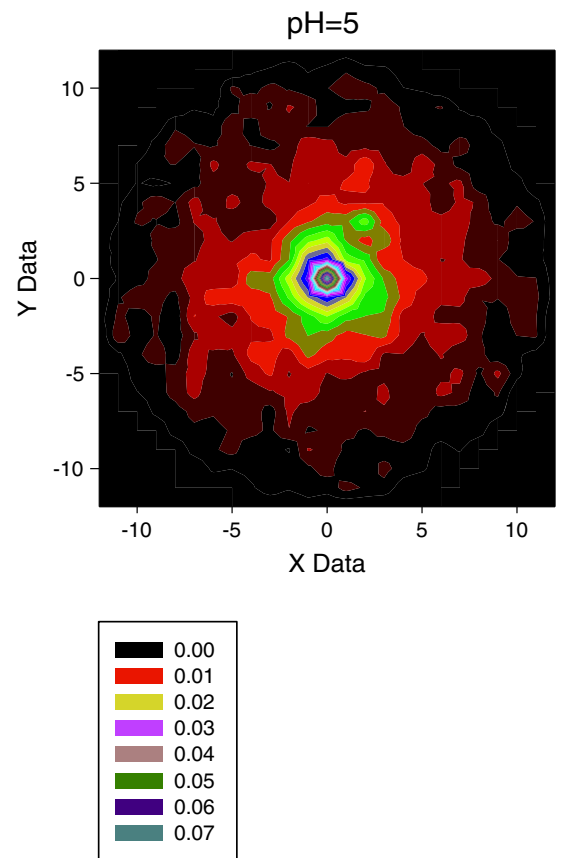
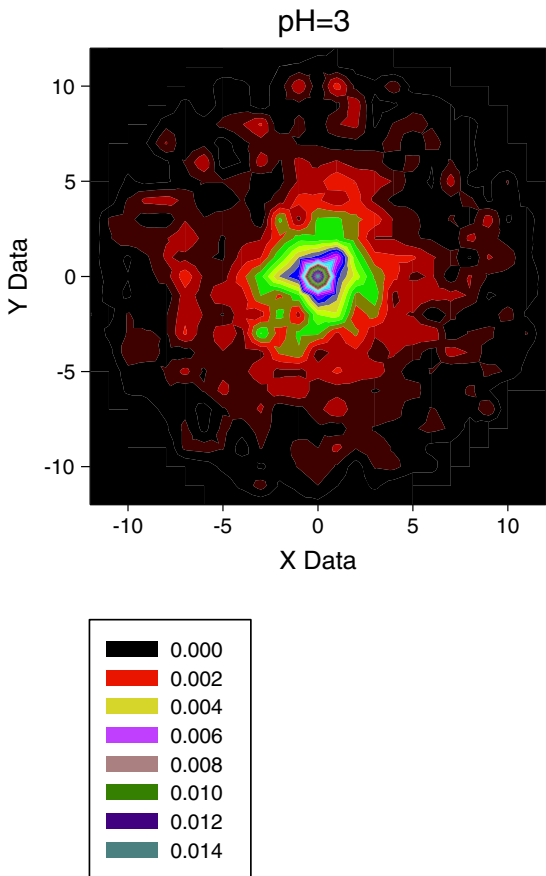

Fig. 3a-c Density profile of the monovalent salt. a $\mathrm{pH} 8, \mathbf{b} \mathrm{pH} 5$, c $\mathrm{pH} 3$ 

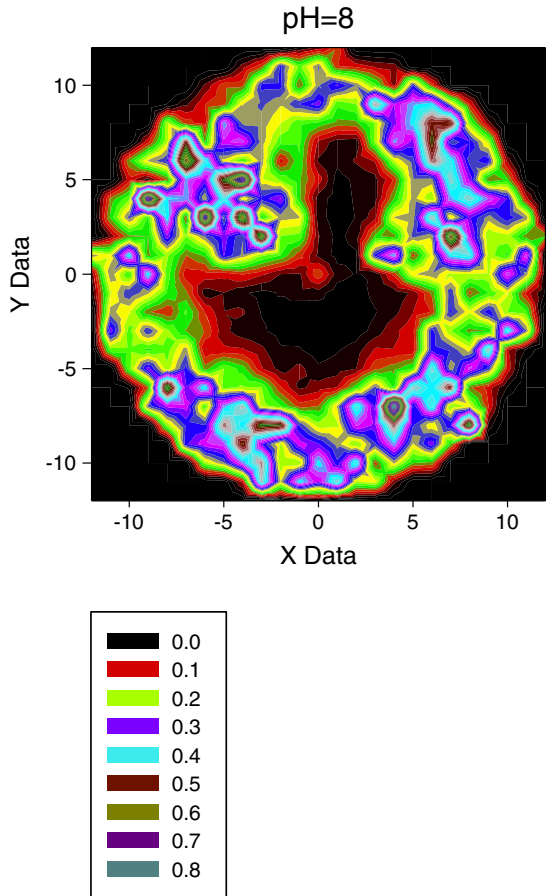

Fig. 4a-c Density profile of the divalent salt. a $\mathrm{pH} 8, \mathbf{b} \mathrm{pH} 5$, c $\mathrm{pH} 3$

and the corresponding changes of the effective surface charge can be seen through changes in channel conductance. Ali et al. [25] recently found that calcium binding to fixed charged groups confined over nanoscale regions is relevant to ion equilibrium and transport in the ionic channels of cell membranes and artificial nanopores.
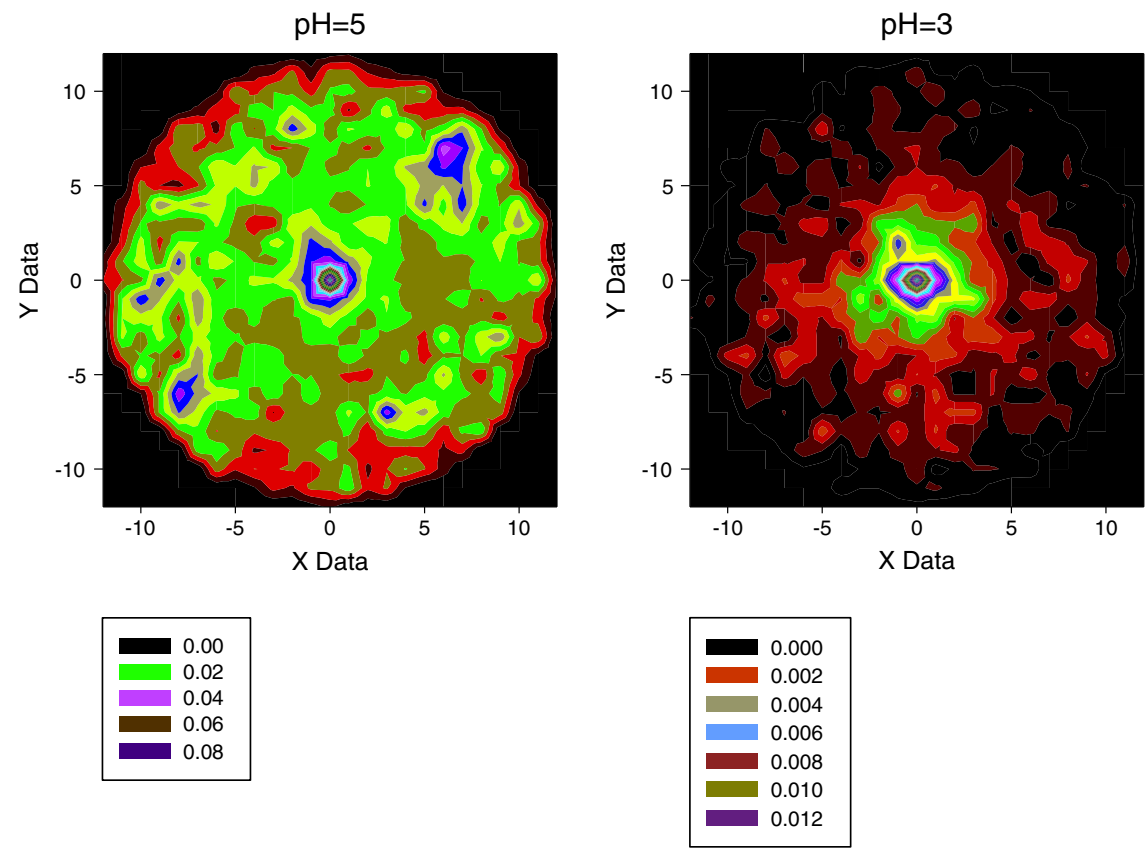
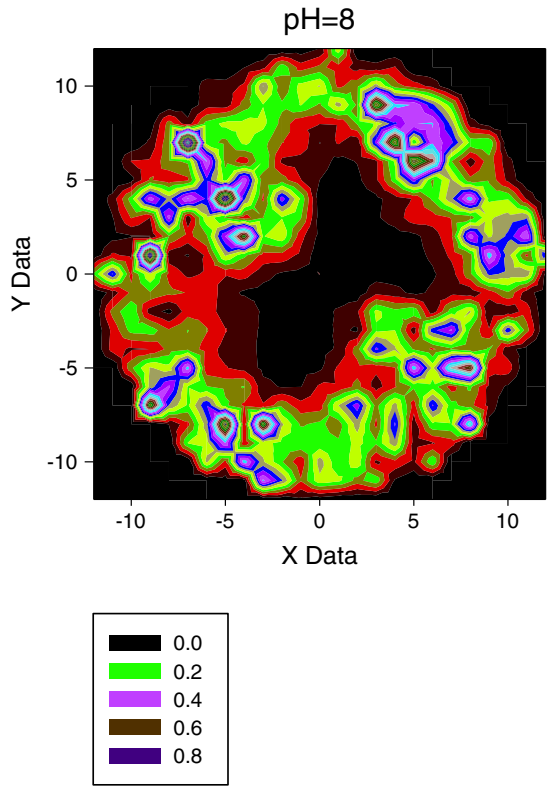

Analysis of density profiles also confirms the screening mechanism for the anion selectivity in the pores. The density profile for the monovalent salt shows that, at $\mathrm{pH} 8$, the cations are spread all over the nanopore surface (Fig. 3). The concentration is higher near the wall due to the negative charge of the monomers. As the $\mathrm{pH}$ decreases, the concentration
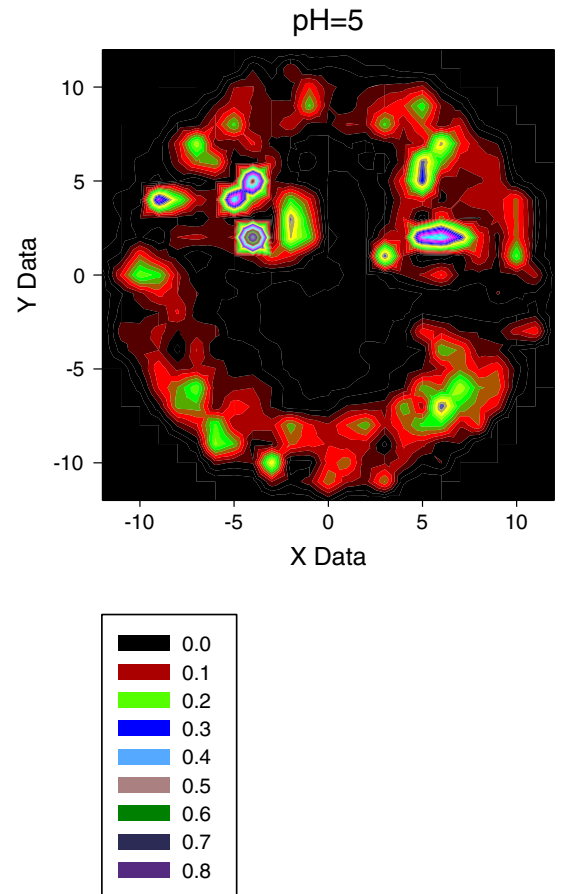
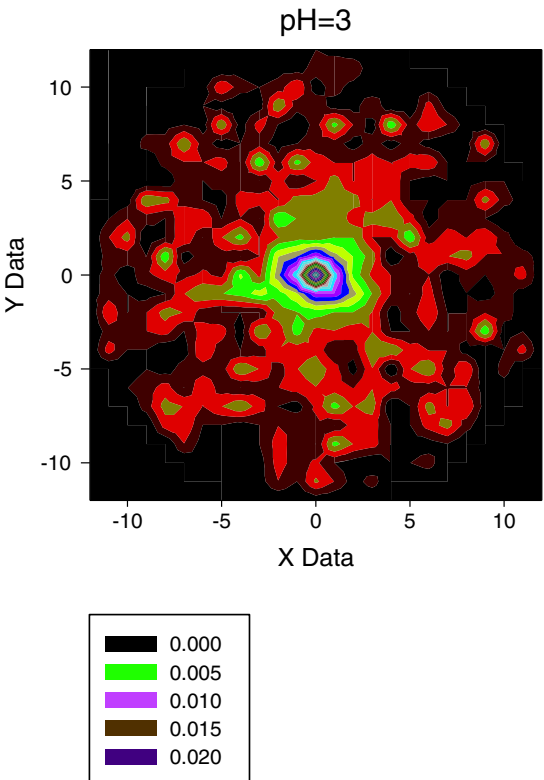

Fig. 5a-c Density profile of the trivalent salt. a pH 8, b pH 5, c pH 3 
near the walls also decreases due to steric impediment since the monomers are now not charged.

For the divalent salt, the binding between the divalent cations and the charged monomers is so strong that, at $\mathrm{pH} 8$, all the anions are concentrated near the wall, close to the polymer brush, and there are no cations in the center of the pore (Fig. 4). The absence of cations in the center of the pore suggests that the monomers and the cations interact in a quelation-type reaction mechanism and therefore the cations would not be involved in the transport of charge since they are attached to the monomers.

In the case of the trivalent salt, the cation concentration at pH 8 is less than for the divalent salt (Fig. 5). This is also an effect of confinement, since every cation now has three charges and the repulsion between them is much higher than in the case of divalent cations. However, the net charge is higher. Unlike the divalent cations, trivalent cations still maintain a high concentration near the wall at $\mathrm{pH} 5$. At $\mathrm{pH} 3$ there is no charge in the system, so the concentration is now higher in the center of the pore.

\section{Conclusions}

In the work reported in this letter, we found that the mechanism of anion selectivity inside nanopores is primarily a consequence of the screening of negative charges by cations.

In the case of monovalent cations, screening is not very effective so anions are rejected. We found an 'off-state' at high $\mathrm{pH}$ and an 'on-state' at low $\mathrm{pH}$.

When there are divalent cations, screening is good and there is no rejection of the anion. The concentration of anions at high $\mathrm{pH}$ is similar to those at low $\mathrm{pHs}$. The system is always in an 'on-state'.

Trivalent cations show an inverse selectivity mechanism: at high $\mathrm{pH}$ the concentration is higher than at low $\mathrm{pH}$, i.e., at high $\mathrm{pH}$ the pore is in the 'on-state' and at low $\mathrm{pH}$ in the 'off-state'.

\section{References}

1. Hille B (2001) Ion channels of excitable membranes. Sinauer, Sunderland

2. Kass I, Arkin IT (2005) How pH opens a $\mathrm{H}^{+}$channel: the gating mechanism of influenza a M2. Structure 13:1789-1798

3. Okada A, Miura T, Takeuchi H (2001) Protonation of histidine and histidine-tryptophan interaction in the activation of the M2 ion channel from influenza a virus. Biochemistry 40:6053-6060

4. Nestorovich EM, Rostovtseva TK, Bezrukov SM (2003) Residue ionization and ion transport through OmpF channels. Biophys J 85:3718-3729

5. Im W, Roux B (2002) Ion permeation and selectivity of OmpF porin: a theoretical study based on molecular dynamics, Brownian dynamics, and continuum electrodiffusion theory. J Mol Biol 322:851-870

6. Roux B, Bernèche S, Egwolf B, Lev B, Noskov SY, Rowley CN, $\mathrm{Yu} \mathrm{H}$ (2011) Ion selectivity in channels and transporters. J Gen Physiol 137:415-426

7. Yu H, Noskov SY, Roux B (2010) Two mechanisms of ion selectivity in protein binding sites. Proc Natl Acad Sci USA 107:20329-20334

8. De Biase PM, Solano CJ, Markosyan S, Czapla L, Noskov SY (2012) BROMOC-D: brownian Dynamics/Monte-Carlo program suite to study Ion and DNA permeation in nanopores. J Chem Theor Comput 8:2540-2551

9. Brunsen A, Cui J, Ceolín M, del Campo A, Soler-Illia GJ, Azzaroni O (2012) Light-activated gating and permselectivity in interfacial architectures combining "caged" polymer brushes and mesoporous thin films. Chem Commun 48:1422-1424

10. Ito Y, Ochiai Y, Park YS, Imanishi Y (1997) pH-sensitive gating by conformational change of a polypeptide brush grafted onto a porous polymer membrane. J Am Chem Soc 119:1619-1623

11. Fan R, Huh S, Yan R, Arnold J, Yang P (2008) Gated proton transport in aligned mesoporous silica films. Nat Mater 7:303-307

12. Siwy ZS, Howorka S (2010) Engineered voltage-responsive nanopores. Chem Soc Rev 39:1115-1132

13. Bayley H, Cremer PS (2001) Stochastic sensors inspired by biology. Nature 413:226-230

14. Maglia G, Heron AJ, Hwang WL, Holden MA, Mikhailova E, Li Q, Bayley H (2009) Droplet networks with incorporated protein diodes show collective properties. Nat Nanotechnol 4:437-440

15. Macrae MX, Blake S, Jiang X, Capone R, Estes DJ, Mayer M, Yang J (2009) A semi-synthetic ion channel platform for detection of phosphatase and protease activity. ACS Nano 3:3567-3580

16. Wilson NA, Abu-Shumays R, Gyarfas B, Wang H, Lieberman KR, Akeson M (2009) Electronic control of DNA polymerase binding and unbinding to single DNA molecules. ACS Nano 3:995-1003

17. Aznar E, Marcos MD, Martínez-Máñez R, Sancenón F, Soto J, Amorós P, Guillem C (2009) pH-and photo-switched release of guest molecules from mesoporous silica supports. J Am Chem Soc 131:6833-6843

18. Brunsen A, Díaz C, Pietrasanta LI, Yameen B, Ceolín M, SolerIllia GJ, Azzaroni O (2012) Proton and calcium-gated ionic mesochannels: phosphate-bearing polymer brushes hosted in mesoporous thin films as biomimetic interfacial architectures. Langmuir 28:3583-3592

19. Im W, Seefeld S, Roux B (2000) A grand canonical Monte CarloBrownian Dynamics algorithm for simulating ion channels. Biophys J 79:788-801

20. He Y, Gillespie D, Boda D, Vlassiouk I, Eisenberg RS, Siwy ZS (2009) Tuning transport properties of nanofluidic devices with local charge inversion. J Am Chem Soc 131:5194-5202

21. Carnal F, Stoll S (2011) Adsorption of weak polyelectrolytes on charged nanoparticles. Impact of Salt Valency, $\mathrm{pH}$, and nanoparticle charge density. Monte Carlo simulations. J Phys Chem B 115:12007-12018

22. Barr SA, Panagiotopoulos AZ (2012) Conformational transitions of weak polyacids grafted to nanoparticles. J Chem Phys 137:144704-144710

23. Fornasiero F, Park HG, Holt JK, Stadermann M, Grigoropoulos CP, Noy A, Bakajin O (2008) Ion exclusion by sub-2-nm carbon nanotube pores. Proc Natl Acad Sci USA 105:17250-17255

24. Gurnev PA, Bezrukov SM (2012) Inversion of membrane surface charge by multivalent cations probed with a cation-selective channel. Langmuir 28:15824-15830

25. Ali M, Nasir S, Ramirez P, Cervera J, Mafe S, Ensinger W (2012) Calcium binding and ionic conduction in single conical nanopores with polyacid chains: model and experiments. ACS Nano 6: 9247-9257 